\title{
0 efeito da escola básica brasileira
}

\author{
RENATO JÚDICE DE ANDRADE*
}

JOSÉ FRANCISCO SOARES ${ }^{*}$

\section{RESUMO}

O desempenho cognitivo de um aluno, medido pela sua proficiência em testes padronizados, é fruto de suas opçóes pessoais, de seus antecedentes sociodemográficos, da estrutura e valores de sua família e da sociedade em que vive e, finalmente, da escola em que estuda. O objetivo deste trabalho é caracterizar, de duas maneiras distintas, o efeito das escolas de educação básica brasileira sobre o desempenho cognitivo de seus alunos. Como existem muitos outros determinantes, o efeito da escola só pode ser isolado e medido com o auxílio de modelos estatísticos que controlam a influência dos outros fatores. Para isto, este trabalho usa os modelos hierárquicos de regressão. O estudo empírico utiliza os dados do Sistema Nacional de Avaliação da Educação Básica (Saeb), referentes aos ciclos de 1995, 1997, 1999, 2001 e 2003; da $4^{\mathrm{a}}$ e $8^{\mathrm{a}}$ séries do ensino fundamental e da $3^{\mathrm{a}}$ série do ensino médio, tanto em Matemática como em Língua Portuguesa. Os resultados da pesquisa aqui relatada mostram a existência de escolas, no nosso sistema educacional, com efeito diferenciado e que, portanto, detêm informaçôes sobre a gestão pedagógica de seus recursos humanos e físicos que, se usados em um número maior de escolas, podem melhorar o sistema brasileiro de educaçáo básica.

Palavras-chave: escolas, Saeb, desenvolvimento cognitivo, alunos, qualidade do ensino, educação básica.

\section{RESUMEN}

El desempeño cognoscitivo de un alumno, medido por su competencia en exámenes estandarizados, es fruto de sus opciones personales, de sus antecedentes sociodemográficos, de

\footnotetext{
* Professor do Centro Universitário Newton Paiva, Consultor e Diretor da Quali-E Consultoria Educacional e Coordenador Executivo da Avalia Educacional (judice@quali-e.com.br).

** Professor da Faculdade de Educação da Universidade Federal de Minas Gerais e Consultor da Avalia Educacional (francisco-soares@ufmg.br).
} 
la estructura y valores de su familia y de la sociedad en la que vive y, finalmente, de la escuela en la que estudia. El objetivo de este trabajo es caracterizar, de dos maneras distintas, el efecto de las escuelas de educación básica brasileña sobre el desempeño cognoscitivo de sus alumnos. Como existen muchos otros determinantes, el efecto de la escuela sólo puede ser aislado y medido con el auxilio de modelos estadísticos que controlan la influencia de los otros factores. Para tal fin, este trabajo usa los modelos jerárquicos de regresión. El estudio empírico utiliza los datos del Sistema Nacional de Evaluación de la Educación Básica (Saeb), referentes a los ciclos de 1995, 1997, 1999, 2001 y 2003; del $4^{\circ}$ y $8^{\circ}$ años de la enseñanza fundamental y del $3^{\circ}$ año de la enseñanza media, tanto en Matemática como en Lengua Portuguesa. Los resultados de la investigación muestran la existencia de escuelas en nuestro sistema educativo con un efecto diferenciado y que, por lo tanto, poseen informaciones sobre la gestión pedagógica de sus recursos humanos y físicos que si se usasen en un número mayor de escuelas podrían mejorar el sistema brasileño de educación básica.

Palabras clave: escuelas, Saeb, desarrollo cognoscitivo, alumnos, calidad de la enseñanza, educación básica.

\section{ABSTRACT}

A student's cognitive performance, as measured by his proficiency in standardized tests, is a result of his personal options, his socio-demographic antecedents, his family's structure and values and the society in which he lives and, finally, the school he attends. The purpose of this article is to characterize, in two distinct ways, the effect of Brazil's elementary schools on their students' cognitive performance. As there are many other determining factors, the school's effect can only be isolated and measured by means of statistical methods which control the influence of other factors. For this purpose, this research makes use of hierarchical regression models. The empirical study uses data from the Saeb (National Assessment System of Basic Education), concerning the 1995, 1997, 1999, 2001 and 2003 cycles; from the 4th and 8th grade of elementary school and the 3rd grade of high school (senior year), both in Mathematics and in Portuguese. The results of the research point to the existence of schools, in our educational system, with a distinct effect thus showing that they have information about the pedagogical management of their human and physical resources which, if used by a larger number of schools, may improve Brazil's system of elementary education.

Keywords: schools, Saeb, cognitive development, students, teaching quality, basic education. 


\section{INTRODUÇÃO AO PROBLEMA}

Hoje a sociedade brasileira espera que a escola de educaçáo básica garanta a seus alunos o aprendizado das competências necessárias para uma inserçáo crítica e produtiva na sociedade. Tais competências, que sáo de natureza cognitiva, cultural e ética incluem a formação de hábitos, o convívio com diferentes e a solução pacífica de conflitos.

Neste texto, o conceito de "efeito da escola" terá, entretanto, uma definição mais restrita, referindo-se somente à influência da escola no desempenho cognitivo de seus alunos. No Brasil, a medida desse efeito só se tornou possível com a consolidação do Saeb, como afirmam Brooke e Soares (2008):

A consolidação do SAEB - Sistema de Avaliação da Educação Básica a partir de 1995 e a conseqüente publicação regular de dados comparáveis sobre o desempenho dos alunos da educação básica provocaram uma mudança profunda na forma de analisar os sistemas de ensino no Brasil. Após o SAEB, os sistemas educacionais puderam ser analisados não só em relaçáo à sua capacidade de atendimento às crianças em idade escolar, mas também em relação ao aprendizado de seus alunos. Pela primeira vez, tornou-se possível avaliar aquelas características das escolas que mais se associavam à aprendizagem. Mediante o cruzamento de informaçóes sobre as condiçóes de funcionamento das escolas, as características socioeconômicas dos alunos e o nível de aprendizagem alcançado, a pesquisa brasileira começou a quantificar o efeito-escola e a desvendar as especificidades da escola eficaz. (p. 9)

Ou seja, o conceito de "efeito da escola" é utilizado para medir a capacidade de as escolas, por meio de seu projeto pedagógico e de suas políticas internas, influenciarem o desempenho cognitivo de seus alunos.

Os estudos para a caracterização do efeito das escolas e dos fatores e estruturas promotoras de desempenho surgiram como contraponto aos resultados pessimistas obtidos pelo Relatório Coleman (Coleman et al., 1966). Hoje se sabe que a escola pode fazer diferença no aprendizado do aluno, ainda que sozinha náo possa nem ser responsabilizada por todas as dificuldades dos alunos, nem por todos os seus sucessos. Sobre isso, ver, por exemplo, a ampla revisão da literatura elaborada por Teddlie e Reynolds (2000), que aborda desde aspectos históricos e empíricos da pesquisa sobre o efeito das escolas até a metodologia e características científicas dessa linha de pesquisa.

Essa literatura tem concluído que:

embora parte importante da explicação dos baixos níveis de desempenho dos alunos esteja em fatores extra-escolares, há uma enorme variação entre resultados de escolas de um mesmo sistema que atendem alunos muito similares em termos 
socioeconômicos. Ou seja, a unidade escolar freqüentada pelo aluno pode fazer diferença significativa na sua vida escolar. (Brooke; Soares, 2008, p. 9)

Soares (2008) propóe um modelo conceitual que relaciona cinco estruturas associadas ao desempenho cognitivo dos alunos: o aluno, sua família, a escola e a rede, ou sistema a que está associado, e finalmente a sociedade em geral. $\mathrm{O}$ autor registra que hoje está estabelecido, além da dúvida razoável, que tanto os fatores intra-escolares quanto os extra-escolares estão ligados ao desempenho dos alunos. Mesmo restringindo-se aos fatores ligados à escola, o

modelo mostra que são tantos os fatores escolares associados ao desempenho dos alunos que nenhum deles é capaz de garantir, isoladamente, bons resultados escolares. A ênfase dada a fatores específicos em alguns momentos históricos deve ser atribuída mais à fé dos que os advogam, e não a evidências científicas. (Soares, 2004, p. 5)

Figura 1 - Modelo conceitual explicativo da proficiência

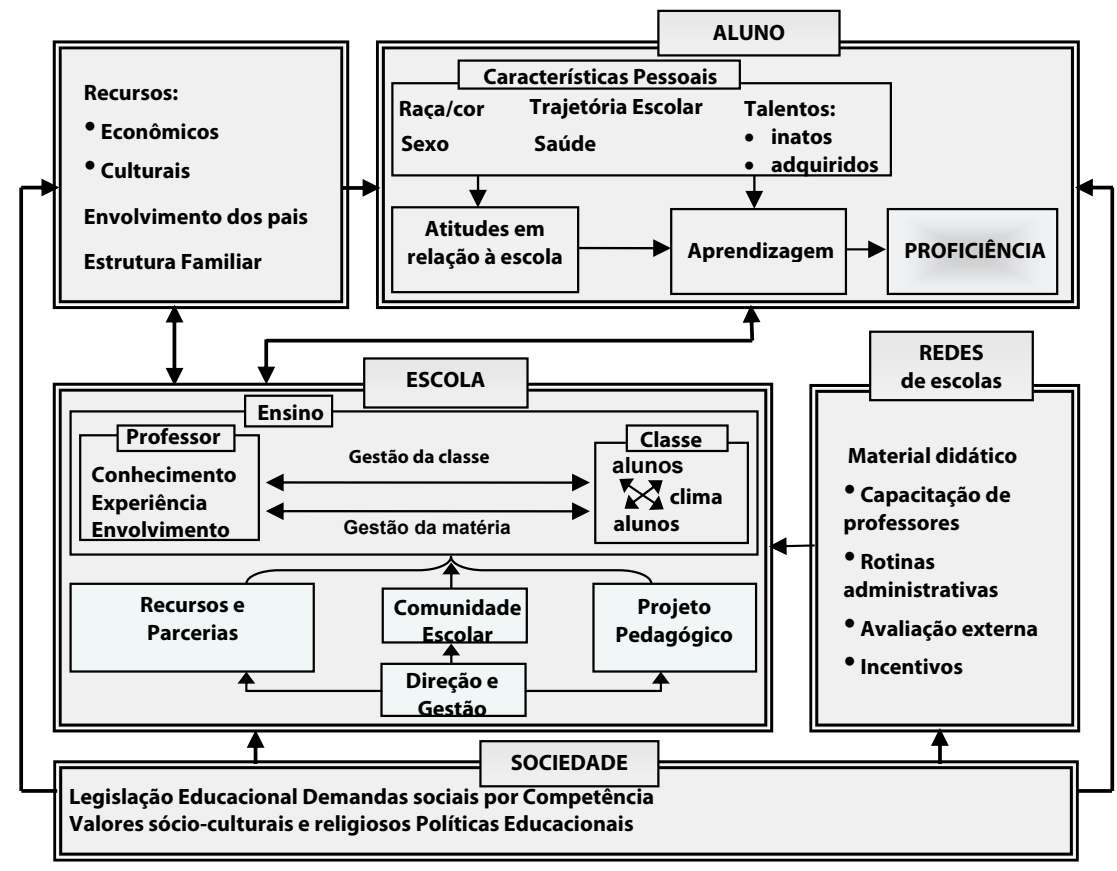

Fonte: Soares, 2002.

Como dito, o objetivo deste texto é caracterizar, por meio de medidas, o efeito das escolas, o que exige a explicitação dos modelos estatísticos e dos dados. Isto será feito na próxima seção. 


\section{DADOS E MODELOS}

Para se estudar o problema de como medir o efeito da escola básica brasileira, foram utilizados os dados de proficiência em Matemática e Leitura e as informaçóes coletadas nos questionários contextuais de cinco ciclos do Sistema Nacional de Avaliação da Educação Básica (Saeb), 1995, 1997, 1999, 2001 e 2003, nas três séries avaliadas, $4^{\mathrm{a}}$ e $8^{\mathrm{a}}$ séries do ensino fundamental e $3^{\mathrm{a}}$ série do ensino médio (Brasil, 2006).

O Saeb foi implantado pelo Instituto Nacional de Estudos e Pesquisas Educacionais Anísio Teixeira (Inep), órgão do Ministério da Educação, em 1990, e é um estudo amostral representativo dos alunos de cada uma das unidades da federação. A partir de 1995, o Saeb passou a utilizar uma metodologia que permite a comparação das proficiências dos alunos entre séries e no decorrer dos anos. Para isto, as análises são feitas por meio da Teoria de Resposta ao Item (TRI) (Valle, 2000; Hambleton; Swaminathan; Rogers, 1991; Hambleton, 1993). O nível de competência de um determinado aluno é associado a um número em uma escala, cujos pontos têm interpretaçóes pedagógicas.

Um dos destaques da pesquisa relatada neste trabalho é a utilização de trinta bases do Saeb (3 séries x 2 disciplinas x 5 ciclos). Estudos anteriores relacionados ao efeito da escola têm sido publicados utilizando-se apenas uma dessas bases do Saeb (Barbosa; Fernandes, 2001; Andrade; Franco; Carvalho, 2003; Soares; Candian, 2007). O cálculo do efeito da escola em vários anos permite analisar a estabilidade dessa medida ao longo de praticamente dez anos.

\subsection{Modelo de análise}

A técnica de regressão linear múltipla é muito utilizada para se estudar a relação entre uma variável dependente, ou resposta, e outras variáveis, denominadas variáveis explicativas ou covariáveis. No entanto, esta técnica não considera o fato, corriqueiro em situaçóes escolares, que os diferentes alunos de uma turma ou escola se influenciam mutuamente e, portanto suas proficiências não são independentes. $\mathrm{Ou}$ seja, o dado educacional é naturalmente mais complexo e exige assim instrumentos de modelagem com um nível comparável de complexidade (Goldstein, 2001, p. 86). A solução encontrada e desenvolvida concomitantemente por Goldstein no Instituto de Educação da Universidade de Londres e Bryk e Randenbush na Universidade de Harvard é hoje denominada modelos hierárquicos ou multiníveis, que se tornaram padrão em pesquisa educacional empírica (Lee, 2001b).

Esses modelos incorporam 
naturalmente, e de uma forma parcimoniosa, a estrutura hierárquica ou de agrupamento da população em estudo, tratando o intercepto e os coeficientes de inclinação como variáveis aleatórias. Desta forma, o modelo permite a variabilidade das estimativas entre os grupos. (Ferrão, 2003, p. 31)

Esta técnica estatística permite captar a complexidade da relação entre os fatores de cada um dos níveis e como esses níveis se influenciam mutuamente. Além disso, os dados de alunos são utilizados nos modelos de análise, mas o interesse analítico é a organização escolar (Soares et al., 2004)1. Ou como argumenta Lee (2001a), existem algumas questóes de pesquisa que são intrinsecamente multíniveis, e, portanto, utilizar técnicas analíticas de um único nível implica uma série de limitaçóes. A modelagem multinível é que proporciona uma abordagem capaz de lidar adequadamente com questóes multiníveis. Para detalhes técnicos sobre os modelos multinível sugere-se Ferrão (2003), Raudenbush e Bryk (2002) e Natis (2001).

A escolha do modelo hierárquico de análise, ou melhor, das variáveis, tanto do nível do aluno como do nível da escola, que constarão desse modelo, deve refletir os objetivos da questão de pesquisa e assim constitui-se em etapa fundamental de todo o processo de modelagem dos dados.

Análises feitas previamente sobre a influência do nível socioeconômico (NSE) no desempenho escolar dos alunos justificam que o estudo de qualquer realidade educacional, em especial a brasileira, deve necessariamente considerar a condição socioeconômica dos alunos (Soares; Andrade, 2005). Além disso, suas características sociodemográficas tais como o sexo, a cor/raça e o atraso escolar sintetizam importantes experiências vividas e que impactam, ainda que de forma distinta, o seu desempenho. Assim, tais variáveis também devem ser incluídas como controle no modelo de análise.

Mas não são apenas as variáveis individuais que afetam a proficiência dos alunos. Ao contrário, o efeito coletivo dessas características tem um impacto ainda maior.

Este é um ponto importante e freqüentemente pouco apreciado. $\mathrm{O}$ impacto dos fatores sociais do coletivo freqüentado pelo aluno, por exemplo, sua escola, no desempenho do aluno é maior do que no nível individual. Ou seja, o aluno que convive com colegas de alta condição social ou cultural é particularmente

${ }^{1} \mathrm{O}$ que é muito relevante, tendo em vista que "esses modelos produziram uma solução para o sério problema da unidade de análise, cujo equacionamento limitou durante anos a análise de dados provenientes de organizaçóes" (Soares et al., 2004, p. 21). 
privilegiado. Seguindo as recomendações de Willms e Somers (2000), incluímos entre as características das escolas utilizadas como controle a média do nível socioeconômico e a média do atraso escolar dos alunos da escola. Willms e Somers justificam o uso desses fatores citando estudos realizados em vários países que mostram que escolas e mesmo salas de aula com alunos de posição social mais alta e/ou de maior nível cognitivo tendem a desfrutar de várias vantagens associadas ao contexto criado por esses alunos. Em média, essas escolas têm maior apoio dos pais, menor número de problemas disciplinares e um clima que valoriza a obtenção de melhores resultados. Além disso, com maior facilidade atrai e mantém professores talentosos e motivados. Todas essas condiçôes caracterizam o que na literatura é chamado de "efeito dos pares", observado quando alunos privilegiados social e culturalmente freqüentam a mesma escola.[...] A não consideração de todos estes fatores de controle é fonte geradora de muitas imprecisôes principalmente na grande imprensa, onde muitos fatores apontados como decisivos para a melhoria do sistema educacional são apenas expressóes destes fatores antecedentes. (Soares et al., 2004, p. 21)

Concordando com essa visão, este trabalho utiliza como variáveis de controle no nível da escola a média do nível socioeconômico, a média do atraso escolar dos alunos e a dependência administrativa (rede) da escola.

No entanto é preciso esclarecer que não há um consenso sobre a escolha das variáveis de controle. Em algumas situações argumenta-se que o controle pelo NSE da escola pode obscurecer o bom trabalho realizado pelo corpo docente das escolas que atraem os alunos de maior NSE. Neste trabalho, entretanto, tais escolhas se justificam por produzir um teste bastante rigoroso para a importância de qualquer fator escolar. Adota-se, portanto a lógica do efeito tipo B proposta por Willms e Raudenbush (1989). ${ }^{2}$

${ }^{2}$ Willms e Raudenbush (1989) definem dois tipos de estimativa do efeito das escolas: efeito tipo A e efeito tipo B. Para estimar o efeito Tipo A são usados modelos estatísticos que incluem fatores de controle associados ao aluno, como uma medida do nível socioeconômico e de seu desempenho prévio. $\mathrm{O}$ efeito tipo A corresponde à estimativa do desempenho escolar esperado para um aluno com características "médias" matriculado na escola X comparando com o desempenho médio de todos os alunos. Por exemplo, se a média geral dos alunos é 7,1 e o efeito da escola X é 0,8, então podemos estimar uma nota de 7,9 para este aluno. Este efeito tem interesse para os pais que querem ter uma expectativa do resultado da escola sobre os seus filhos. A estimativa do efeito Tipo B requer modelos que agreguem além dos fatores de controle usados para o cálculo do efeito Tipo A, fatores contextuais que fogem ao controle da 
$\mathrm{Na}$ literatura brasileira, ainda não há um consenso sobre o uso de dois níveis nos modelos de análise. Gremaud, Felício e Biondi (2006) propóem um modelo com apenas um nível, o da escola. Neste trabalho optou-se por manter dois níveis - o do aluno e o da escola. Evita-se, assim, incorrer num vício de agregação que afetaria a estimativa do efeito das escolas, o que poderia ocorrer caso se utilizasse um modelo de um nível com os resultados dos alunos agregados.

O modelo apresentado nas equações (1) e (2), em dois níveis, é utilizado para o cálculo do efeito da escola em Matemática e Leitura. Nele, destaca-se a opção por retirar da proficiência do aluno o efeito das variáveis demográficas, variáveis sociológicas e variáveis que sintetizem a trajetória escolar desse aluno, completamente fora do controle da escola.

Nível 1: $\quad Y_{i j}=\beta_{0 j}+\beta_{1 j} N_{i j}+\beta_{2 j} \operatorname{SEXO}_{i j}+\beta_{3 j}$ PARDO $_{i j}+\beta_{4 j}$ PRETO $_{i j}+$ $\beta_{5 j}$ ATRASO $_{i j}+\beta_{6 j}$ DISCIPLINA $_{i j}+\beta_{7 j} \operatorname{ATITUDE~}_{i j}+r_{i j}$

Nível 2: $\quad \beta_{0 j}=\gamma_{00}+\gamma_{01}$ MNSE $_{j}+\gamma_{02} \operatorname{REDE}_{j}+\gamma_{03}$ MATRASO $_{j}+u_{0 j}$

$$
\begin{aligned}
& \beta_{1 j}=\gamma_{10} \\
& \beta_{2 j}=\gamma_{20} \\
& \beta_{3 j}=\gamma_{30} \\
& \beta_{4 j}=\gamma_{40} \\
& \beta_{5 j}=\gamma_{50} \\
& \beta_{6 j}=\gamma_{60} \\
& \beta_{7 j}=\gamma_{70}
\end{aligned}
$$

Onde $r_{i j} \sim N\left(0, \sigma^{2}\right)$ e $\left(\begin{array}{l}u_{0 j} \\ u_{1 j}\end{array}\right) \sim N\left[\left(\begin{array}{l}0 \\ 0\end{array}\right),\left(\begin{array}{l}\tau_{00} \tau_{01} \\ \tau_{10} \tau_{11}\end{array}\right)\right]$

escola, oriundos, por exemplo, da composição do corpo discente. O efeito Tipo B estima qual o desempenho da escola $\mathrm{X}$ em comparação com outras escolas com contextos semelhantes. Este efeito interessa mais aos atores envolvidos nas decisóes sobre políticas e práticas educacionais (diretores, professores e gestores públicos), que podem obter uma medida comparativa das escolas equalizadas por suas respectivas clientelas. 
onde:

- $\quad \mathrm{Y}_{\mathrm{ij}}$ é a proficiência, em Matemática ou em Leitura, do i-ésimo aluno da escola $^{3} \mathrm{j}$;

- $\quad \beta_{0 j}$ é a proficiência média dos alunos da escola j;

- $\quad \beta_{1 j}$ é o efeito do NSE do aluno na sua proficiência;

- $\quad \mathrm{NSE}_{\mathrm{ij}}$ é o NSE do aluno centrado na média do grupo, i.e., quão distante da média da escola o NSE do aluno está;

- $\quad \mathrm{SEXO}_{\mathrm{ij}}, \mathrm{PARDO}_{\mathrm{ij}}$, PRETO $_{\mathrm{ij}}$, DISCIPLINA $_{\mathrm{ij}}$ e REDE $\mathrm{R}_{\mathrm{ij}}$ são variáveis indicadoras e estão melhor descritas na tabela 1;

- $\quad$ ATRASO $_{\mathrm{ij}}$ é uma medida discreta do número de anos que o aluno está atrasado em relação à série adequada para a sua idade;

- $\quad$ ATITUDE $_{\mathrm{ij}}$ é uma medida da postura do aluno frente ao ensino, variável que foi centrada na média do grupo, isto é, quão distante da média da escola a ATITUDE do aluno está;

- $\quad$ MATRASO $_{j}$ é a média do atraso escolar dos alunos que compõem a escola j;

- $\quad \gamma_{00}$ é a proficiência média dos alunos da população em questão;

- $\gamma_{01}$ é o efeito do NSE da escola na proficiência do aluno;

- $\quad \mathrm{MNSE}_{\mathrm{j}}$ é o NSE médio da escola j centrado na média total, i.e., quão distante da média geral o NSE da escola está;

- $\mathrm{u}_{0 \mathrm{j}}$ é o efeito associado a j-ésima escola, com variância $\sigma_{u 0}^{2}$ entre escolas, i.e., $\sigma_{u 0}^{2}=\operatorname{Var}\left(\mathrm{u}_{0 j}\right)$;

- $\quad r_{i j}$ é o resíduo associado ao i-ésimo aluno da escola $\mathrm{j}$, com variância $\sigma_{r}^{2}$ intra-escolas, i.e., $\sigma_{r}^{2}=\operatorname{Var}\left(\mathrm{r}_{\mathrm{ij}}\right)$.

A inclusão da variável disciplina é uma necessidade com os dados do Saeb. Trata-se de uma variável indicadora que permite o cálculo de um efeito único por escola com um número maior de alunos. Quando pertinente, a variável disciplina é excluída do modelo e trabalham-se, separadamente, as bases com as proficiências em Matemática e em Leitura. Essa variável não está presente no modelo como uma variável de controle do aluno. Sua inserção apenas pos-

${ }^{3}$ O Saeb é um estudo no qual os alunos não formam uma amostra da escola. Tem-se, na verdade, uma amostra de turmas da escola. Este ponto é crucial para a definiçãa dos modelos a serem considerados, pois o mais correto seria falar em "efeito turma", e não em "efeito-escola". Propóe-se, então, a idéia de pseudo-escola para cada turma amostrada. Apesar disto, por abuso de linguagem, continuaremos a nos referir ao "efeito das escolas". 
sibilita o trabalho com uma base única, na qual a variável dependente passa a ser o desempenho cognitivo do aluno. A metodologia amostral do Saeb também sugere uma decisão nesse sentido, afinal o que são amostradas são turmas de uma escola e, dentro dessa turma, aproximadamente metade dos alunos responde ao teste de Matemática, e a outra metade ao teste de Leitura. Ou seja, a inserção da variável disciplina no modelo proporciona um ganho, pois permite um número maior de observações por escola (Albernaz; Franco; Ferreira, 2002).

A tabela 1 apresenta uma descrição mais detalhada das variáveis incluídas no modelo.

\section{O EFEITO DA ESCOLA}

Hoje, na literatura, há duas definiçóes do conceito de efeito da escola. A primeira refere-se a uma medida específica para cada escola que registra o efeito daquela unidade escolar sobre o aprendizado de seus alunos; consiste na parcela da proficiência do aluno que pode ser atribuída às práticas da escola. A segunda é uma medida do efeito global das escolas de um determinado grupo de referência, com base numa partição da variância dos resultados dos alunos, isto é, se esse efeito é grande, há diferenças entre estudar em uma ou outra escola (Brooke; Soares, 2008). Essas duas definiçóes estão presentes no modelo acima. A primeira trata-se do termo $u_{0 j}$ e a segunda é captada no quociente entre a variância do $u_{0 j}$ e a soma das variâncias do $u_{0 j}$ e $r_{i j}$.

Inicialmente, focaremos a medida individual do efeito da escola, que foi introduzida por Willms (1992). Esta merece destaque, entre outras razóes, por apresentar criticamente a forma de cálculo do efeito da escola por meio dos modelos estatísticos escolhidos para análise. Willms (op. cit.) deixa claro que a interpretação dos efeitos depende da compreensão dos modelos subjacentes. Ou seja, depende das escolhas feitas sobre quais variáveis compóem o modelo. Diferentes agentes podem se interessar por formas de controle diferenciadas. Neste trabalho, como já foi citado, optou-se por um controle mais rigoroso do efeito da escola. Esta opção metodológica que se aproxima do "efeito tipo B" proposto por Willms e Raudenbush (1989). $\mathrm{O}$ estudo deste efeito é considerado mais adequado para a formulação e análise de políticas públicas educacionais. Ao contrário do "efeito tipo A", mais interessante aos pais dos alunos, interessados no efeito da escola, sem distinção da origem deste efeito. Neste caso os modelos de análise náo incluem variáveis de controle das características internas da escola. 
Tabela 1 - Descrição das variáveis incluídas no modelo base

\begin{tabular}{|c|c|c|}
\hline Variável & Descrição & Forma de Medida \\
\hline NSE & Nível socioeconômico* & Escala contínua variando de 0 a 10. \\
\hline ATRASO & Atraso escolar & $\begin{array}{l}\text { Variável discreta: } \\
0 \text { - Regular } \\
1-1 \text { ano atrasado } \\
2-2 \text { anos atrasado } \\
3-3 \text { anos atrasado } \\
4-4 \text { anos atrasado } \\
5-5 \text { anos atrasado ou mais }\end{array}$ \\
\hline SEXO & Sexo do aluno & $\begin{array}{l}\text { Variável indicadora: } \\
0 \text { - Masculino } \\
1 \text { - Feminino }\end{array}$ \\
\hline PARDO & Autodeclaração da cor "parda" & $\begin{array}{l}\text { Variável indicadora: } \\
0 \text { - Não pardo } \\
1 \text { - Pardo }\end{array}$ \\
\hline PRETO & Autodeclaração cor "preta" & $\begin{array}{l}\text { Variável indicadora: } \\
0 \text { - Não preto } \\
1 \text { - Preto }\end{array}$ \\
\hline REDE & Rede de ensino & $\begin{array}{l}\text { Variável indicadora: } \\
0 \text { - Pública } \\
1 \text { - Particular }\end{array}$ \\
\hline DISCIPLINA & Disciplina & $\begin{array}{l}\text { Variável indicadora: } \\
0 \text { - Língua Portuguesa } \\
1 \text { - Matemática }\end{array}$ \\
\hline ATITUDE & Atitude ${ }^{* *}$ & Escala contínua obtida via TRI \\
\hline MNSE & $\begin{array}{l}\text { Média do nível } \\
\text { socioeconômico }\end{array}$ & $\begin{array}{l}\text { Nível socioeconômico médio dos alunos de } \\
\text { uma mesma escola }\end{array}$ \\
\hline MATRASO & Média do atraso escola & $\begin{array}{l}\text { Atraso escolar médio dos alunos de uma } \\
\text { mesma escola }\end{array}$ \\
\hline \multicolumn{3}{|c|}{$\begin{array}{l}\text { A variável NSE foi centralizada na média da escola, quando medida no nível do aluno, e na } \\
\text { média geral, quando medida no nível da escola. } \\
\text { " Para o cálculo da variável "Atitude" foi utilizada a mesma metodologia do cálculo do nível } \\
\text { socioeconômico, ou seja, a Teoria de Resposta ao Item (TRI). Como o objetivo aqui também era } \\
\text { sintetizar as informações das } 28 \text { bases do Saeb, o construto acabou sendo composto por três } \\
\text { variáveis obtidas nos questionários contextuais. São elas: 1) Você gosta de estudar Matemática?; } \\
\text { 2) Você gosta de estudar Língua Portuguesa?; e 3) Você faz lição de casa? Sendo que as } \\
\text { alternativas de resposta para essas três questões foram, sempre, "sim" ou "não". }\end{array}$} \\
\hline
\end{tabular}


A medida individual do efeito da escola, $u_{0 j}$, é a diferença entre a performance média de uma escola específica e um nível padráo, controlando-se a performance por características de entrada (perfil do grupo de alunos da escola, características do sistema de ensino, infra-estrutura etc.). Portanto, fica claro que a medida depende das escolas que compóem a amostra. Obtendo-se um valor alto e positivo para uma determinada escola, conclui-se que essa escola possui práticas internas que levam seus alunos a resultados melhores do que era esperado, comparando-se com escolas com características de entrada semelhantes e incluídas na amostra. Obtendo-se valores negativos para esse efeito da escola não significa que os alunos dessa escola específica estão "desaprendendo". A medida apenas indica um desempenho abaixo da média das escolas incluídas no estudo.

O trabalho de Soares, Alves e Oliveira (2001) ilustra bem esse tipo de medida, pois representa um esforço para se medir o efeito das escolas de ensino médio do Estado de Minas Gerais, utilizando-se as bases de dados entáo disponíveis, no caso, as do vestibular da UFMG de 1998, 1999 e 2000. Os autores ajustaram três modelos diferentes com esses dados, e, no contexto deste artigo, o principal resultado encontrado foi justamente que o efeito das escolas muda, isto é, depende do modelo escolhido. O primeiro modelo gera uma medida de efeito da escola que não deve ser utilizada, pois não leva em consideração as características de background do alunado. O segundo modelo já considera tais características, sendo, portanto, de maior interesse aos pais dos alunos em processo de escolha da escola ideal para seu filho, uma vez que ele identifica os estabelecimentos onde os alunos têm maior desempenho, em razão do efeito dessas escolas. E, por fim, o terceiro modelo é o mais rigoroso dos três, uma vez que retira do efeito da escola a parte do desempenho que é atribuída às suas características contextuais. Esse último modelo é similar ao que foi adotado nesta pesquisa e interessa mais aos gestores educacionais, "pois discrimina escolas que estâo apresentando melhores resultados pelos seus próprios méritos" (Soares; Alves; Oliveira, 2001, p. 89).

Ajustando-se o modelo (1) aos dados das bases do Saeb, observa-se que o comportamento da medida do efeito da escola, $u_{0 j}$, é muito semelhante em todos os cinco ciclos estudados. O histograma a seguir ilustra para a base de Matemática 2003, 8a série do ensino fundamental, que a maioria das instituiçóes apresenta um efeito da escola próximo de zero. Isto significa que, na prática, as escolas têm efeito muito próximo entre si.

No entanto, esta constatação geral não pode impedir que se perceba que também existe um número considerável de escolas que estáo impactando, positiva ou 
Gráfico 1 - Efeito da escola em Matemática, 8a série EF, para a base 2003

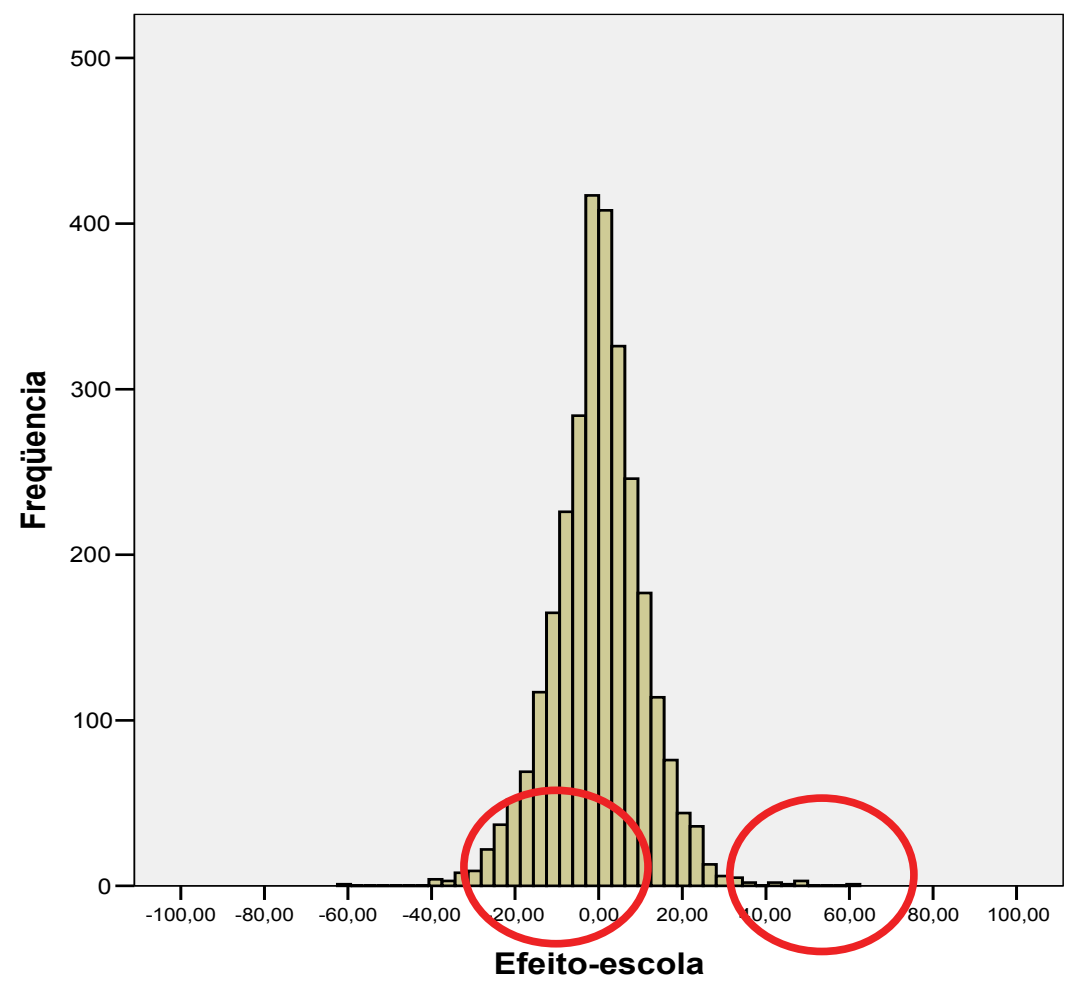

Fonte: elaboração própria com dados do Saeb 2003 - Inep/MEC.

negativamente, o desempenho de seus alunos em mais de 20 pontos de proficiência, valor equivalente a aproximadamente um ano de escolaridade. A tabela 2 explicita tal fato com maior clareza, uma vez que sintetiza o porcentual de escolas, em cada base, que apresenta o $u_{0 j}$ maior ou igual a 20 pontos, tanto positiva quanto negativamente. Entretanto, vale lembrar que este é um efeito relativo e, portanto, se uma escola for retirada da amostra o valor muda.

É digna de nota, em especial, a existência de escolas com efeito positivo e alto, as quais precisam ser mais estudadas, por metodologias qualitativas, para se compreender melhor os fatores que impactam a aprendizagem na realidade brasileira. Nessa linha, vale o registro de uma iniciativa marcante: o "Aprova Brasil - O direito de aprender" (Brasil, 2006) que sintetiza boas práticas existentes em 33 escolas pú- 
blicas do país que tiveram um alto valor para o efeito da escola ${ }^{4}$, de acordo com os resultados da Prova Brasils.

Tabela 2 - Porcentual de escolas, em cada base Saeb, com $u_{0 j}$ (efeito da escola) inferior ou superior a 20 pontos

\begin{tabular}{ccccccc}
\hline \multirow{2}{*}{ Ano } & \multicolumn{3}{c}{$\mathbf{u}_{\mathbf{0 j}} \leq-\mathbf{2 0 , 0}$} & \multicolumn{3}{c}{$\mathbf{u}_{\mathbf{0} \mathbf{j}} \geq \mathbf{2 0 , 0}$} \\
\cline { 2 - 7 } & $\mathbf{4}^{\mathbf{a}} \mathbf{E F}$ & $\mathbf{8}^{\mathbf{a}} \mathbf{E F}$ & $\mathbf{3}^{\mathbf{a}} \mathbf{E M}$ & $\mathbf{4}^{\mathbf{a}} \mathbf{E F}$ & $\mathbf{8}^{\mathbf{a}} \mathbf{E F}$ & $\mathbf{3}^{\mathbf{a}} \mathbf{E M}$ \\
\hline 1995 & - & 7,3 & 8,5 & - & 5,7 & 8,5 \\
1997 & 3,0 & 3,6 & 7,5 & 4,6 & 3,9 & 8,2 \\
1999 & 2,5 & 3,0 & 7,3 & 3,6 & 3,6 & 8,1 \\
2001 & 3,1 & 3,3 & 6,1 & 3,1 & 2,7 & 6,9 \\
2003 & 3,1 & 3,7 & 7,5 & 3,4 & 3,2 & 7,8 \\
\hline
\end{tabular}

Fonte: elaboração própria com dados do Saeb 2003 - Inep/MEC.

No entanto, a imprecisão da medida do efeito da escola é muito grande, tanto que torna inútil qualquer tentativa de hierarquização de escolas segundo o seu efeito. "As estimativas desses trabalhos contêm tanta incerteza estatística que é impossível fazer comparaçóes válidas entre a maioria das escolas" (Goldstein, 2001, p. 91).

Infelizmente, essa postura é extremamente "apreciada" pela imprensa quando há qualquer divulgação de resultados em avaliaçáo educacional, provocando, na maioria das

\footnotetext{
${ }^{4}$ Tendo em vista o contexto deste trabalho, seria desejável citar a metodologia utilizada no "Aprova Brasil - O direito de aprender" para se calcular o efeito da escola. No entanto, nos documentos a que se teve acesso, a única menção a esse índice é de que se trata de um "indicador do impacto que a escola tem na vida e no aprendizado da criança. Pesquisado e testado em estudos em diversas realidades, o Índice é determinado a partir de critérios científicos. As escolas visitadas, pesquisadas e analisadas no estudo 'Aprova Brasil, o direito de aprender' não são exatamente as melhores escolas, mas aquelas com o mais alto 'efeito escola'" (Brasil, 2006, p. 10).

${ }^{5}$ Cada uma dessas 33 escolas foi visitada, e centenas de pessoas foram ouvidas, entre elas, diretores, professores, funcionários, pais e alunos. As crianças que freqüentam essas escolas são filhas de famílias de baixa renda, vivem em municípios pobres ou de difícil acesso, ou em comunidades especialmente vulneráveis. As condiçóes desses meninos e meninas poderiam conspirar para que eles não tivessem bons rendimentos em seus estudos. Mas as relaçóes humanas, a criatividade, a participação, o respeito às condiçôes e saberes de cada um, as práticas pedagógicas e a interação com a comunidade fazem a diferença. As crianças e os adolescentes aprendem e, assim, a escola demonstra toda sua força de transformar para melhor a vida desses meninos e meninas (Brasil, 2006, p. 4).
} 
vezes, conclusões e inferências sem fundamentos. As listas das escolas com o resultado do Exame Nacional do Ensino Médio (Enem) é um exemplo de como "não" se deveria divulgar os resultados. A hierarquizaçáo das escolas causa um tumulto grande, sem, no entanto, contribuir para uma completa compreensão desses resultados e da medida que foi feita. E mais, as escolas mudam frequentemente sua posição no tal ranking, fruto muito mais da incerteza na medida do que dos esforços pedagógicos da comunidade escolar.

O gráfico 2 exemplifica essa inviabilidade, uma vez que hierarquiza as escolas segundo o valor do seu efeito, ao mesmo tempo em que associa o intervalo de confiança para cada medida. O gráfico foi extraído do trabalho de Soares, Alves e Oliveira (2001) e tem como referencial teórico as discussóes propostas inicialmente por Goldstein e Thomas (1996) e detalhadas, em seguida, por Goldstein e Spiegelhalter (1996). Observe-se que não é possível distinguir a diferença entre quaisquer duas escolas. No máximo, podem-se identificar três grandes grupos: um primeiro, mais à esquerda, com as escolas com efeitos mais negativos; um segundo, o mais populoso dos três, ao centro, contendo as escolas cujo efeito é nulo dentro da precisão da medida; e um terceiro, mais à direita, com escolas cujo efeito é positivo. Ou seja, nas palavras de um desses autores, ao comentar a incerteza dessas medidas, "podemos descrever relaçóes estruturais num alto nível de complexidade, mas não podemos medir precisamente a contribuição de cada escola individualmente" (Goldstein, 2001, p. 91).

Gráfico 2 - Intervalo de confiança para os efeitos das escolas estimado pelo modelo 3 , segundo os dados do vestibular de 2000

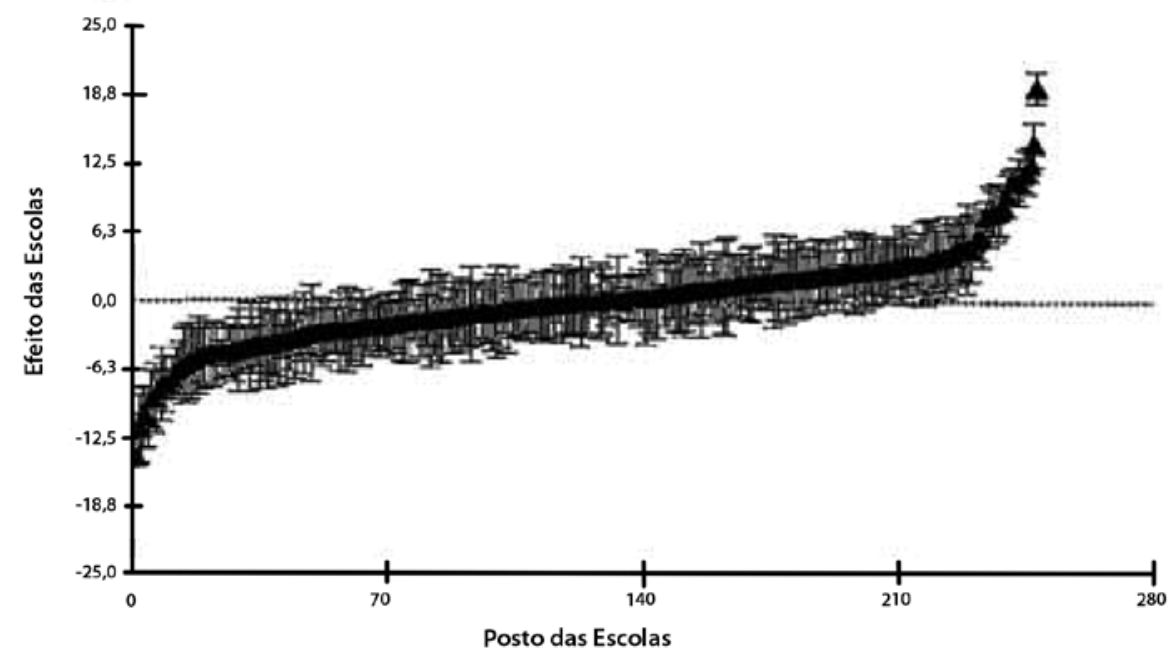

Fonte: Soares; Alves; Oliveira, 2001, p. 90. 


\section{A HETEROGENEIDADE DAS ESCOLAS BRASILEIRAS}

A segunda definição do conceito efeito da escola é o "efeito da escola como medida da proporção da variância total que pode ser atribuída às escolas em relação à variância total dos escores de seus alunos em testes individuais" (Teddlie; Reynolds, 2000, p. 68). Ou seja, essa é uma medida de grupo de escolas e não individual como o primeiro tipo. Observe-se que náo se trata de atribuir uma parcela do desempenho do aluno à escola na qual ele estuda, mas atribuir a responsabilidade de uma parcela da variação dos desempenhos de todos os alunos às características internas de todas as escolas do grupo considerado.

Antes de usar essa definição de efeito da escola é adequado questionar o nome usualmente dado a essa medida. A palavra efeito sugere que quanto maior o valor maior será o seu impacto. Não é, entretanto, o caso dessa medida. Um aumento no porcentual (ou na proporção da variância) indica, apenas, que há uma maior distinção no grupo de escolas. Isto é, há diferenças entre as escolas cujas explicaçôes residem nas características internas das escolas, seu alunado, seu projeto pedagógico, seus professores etc. Daí a opção pelo termo "medida da heterogeneidade" das escolas em detrimento do termo "efeito da escola". $\mathrm{Na}$ verdade, um aumento desse porcentual náo implica um aumento do efeito provocado pela escola, que é uma medida individual. Ele corresponde apenas a uma maior variabilidade dentro do grupo, que agora apresentaria escolas com alto efeito e outras com baixo, ou até com efeito negativo. Por isso, propóe-se uma distinção na qual apenas o primeiro tipo de efeito continue sendo denominado efeito da escola, pois se trata de uma medida individual, enquanto o segundo tipo de efeito passaria a ser denominado medida da heterogeneidade de escolas, por se tratar de uma medida de grupo.

O objetivo específico da introdução desse conceito seria medir quão diferentes são as escolas brasileiras em relação ao desempenho em Matemática e Língua Portuguesa (Leitura) de seus alunos, utilizando-se os dados de cinco ciclos do Sistema Nacional de Avaliação da Educação Básica (Saeb). Ou seja, não se trata de considerar o efeito de cada escola em particular, mas o coeficiente de correlação intra-escolar como estimador da heterogeneidade das escolas, que é dado por:

$$
\rho=\frac{\sigma_{u_{0}}^{2}}{\sigma_{r}^{2}+\sigma_{u_{0}}^{2}}
$$


onde:

- $\quad \rho$ é a medida da heterogeneidade das escolas. Um coeficiente que varia entre 0 e 1, sendo que, quanto mais próximo de 1 mais a variabilidade na proficiência dos alunos deve-se à diferença entre as escolas; e

- $\quad$ os coeficientes $\sigma$ foram definidos na equação (1), no detalhamento do Modelo Base escolhido.

Teddlie e Reynolds (2000) fazem uma revisão bibliográfica considerando a magnitude da heterogeneidade das escolas em estudos internacionais. Estes mostram valores entre 11 e $12 \%$ para as escolas da Holanda, de $12 \%$ para a Alemanha e de $10 \%$ para os EUA. Utilizando dados do Saeb, este trabalho obteve uma medida da heterogeneidade para as escolas brasileiras de 19\% quando se leva em consideração apenas o desempenho em Matemática e 15\% quando se considera como variável dependente a proficiência em Leitura. Como registrado anteriormente, as escolas brasileiras também são muito semelhantes. Registre-se, no entanto, que os valores dos países citados referem-se a um cálculo sem o controle prévio pelo NSE, enquanto os resultados para o Brasil foram obtidos após esse controle. Já a diferença na medida para as duas disciplinas, provavelmente, reside no fato de que a Matemática sofre mais a influência dos fatores escolares, enquanto o estudo da língua materna é mais sensível às variáveis familiares (Barbosa, 2005).

Os gráficos a seguir permitem analisar não só a estabilidade da medida da heterogeneidade de 1995 a 2003, mas também a influência de fatores, como a dependência administrativa e a série dos alunos.

O gráfico 3, considerando-se todas as escolas particulares da amostra, indica que a semelhança entre elas é maior no ensino fundamental que no ensino médio. Há um aumento na heterogeneidade entre escolas com o aumento das séries de estudo, em todos os ciclos considerados. Este gráfico sintetiza os dados de Matemática, mas o mesmo fenômeno é observado em relação aos dados de Leitura. Uma possível explicação para esse maior valor no ensino médio é a forte competição para o vestibular das instituiçóes públicas de ensino superior. Isso faz com que algumas escolas foquem seus trabalhos no desenvolvimento cognitivo de seus alunos, enquanto outras estabelecem prioridades distintas em seus projetos pedagógicos. Uma segunda hipótese, sabendo-se que as escolas diferem bastante entre si, pode estar relacionada com o fato de que as competências desenvolvidas nas séries iniciais, como a alfabetização, por exemplo, sofrem grande influência familiar, enquanto as competências previstas para o ensino médio são de cunho muito mais escolar. Portanto, o efeito 
da escola, seja ele positivo ou negativo, estará muito mais em evidência nas últimas séries do que nas primeiras.

Gráfico 3 - Evolução da heterogeneidade das escolas, por série - Rede Particular, Matemática

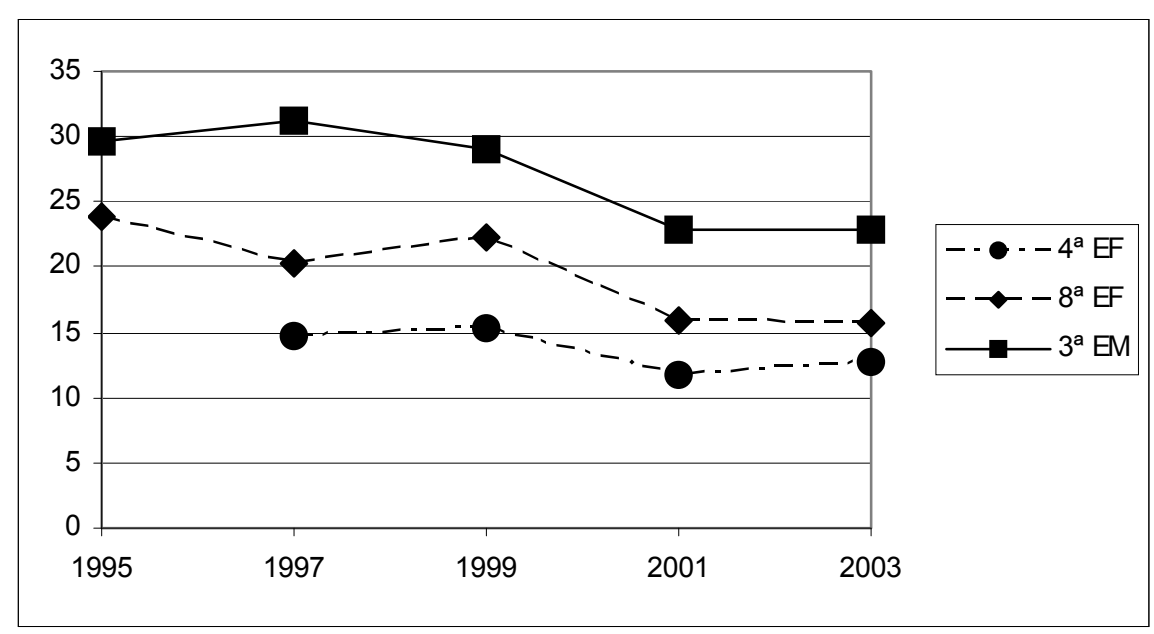

Fonte: elaboração própria com dados do Saeb - Inep/MEC.

Apesar de que se deve considerar uma tendência de queda na heterogeneidade das escolas em relaçáo aos alunos da $3^{\text {a }}$ série do ensino médio, não se pode negar que, para a rede particular do Brasil, esses valores ainda são muito elevados.

Comparando-se o gráfico 3 com os gráficos 4 e 5, a seguir, constata-se que na rede pública a supremacia da heterogeneidade das escolas para a $3^{a}$ série do ensino médio permanece nos ciclos do Saeb dos anos 90. Mas os ciclos de 2001 e 2003 mostram que há maior variação entre as escolas das redes municipal e estadual que atendem a $4^{\mathrm{a}}$ série do ensino fundamental.

Essa inversão de valores na última década pode ser creditada, como mostram os gráficos 4 e 5 , muito mais a uma queda na heterogeneidade das escolas de $3^{\text {a }}$ série do ensino médio do que a um aumento na heterogeneidade das escolas de $4^{a}$ série do ensino fundamental. Essa queda se concentrou, principalmente, entre os anos de 1997 e 2001, porém foi muito mais acentuada na rede pública do que na privada. Isso pode ser explicado pelo grande aumento de matrículas no ensino médio da rede pública, fato não observado na rede particular, que permaneceu com um número de matrículas, praticamente, inalterado. Quanto maior o número de alunos, maior 
Gráfico 4 - Evolução da heterogeneidade das escolas, por série - Rede Municipal, Matemática

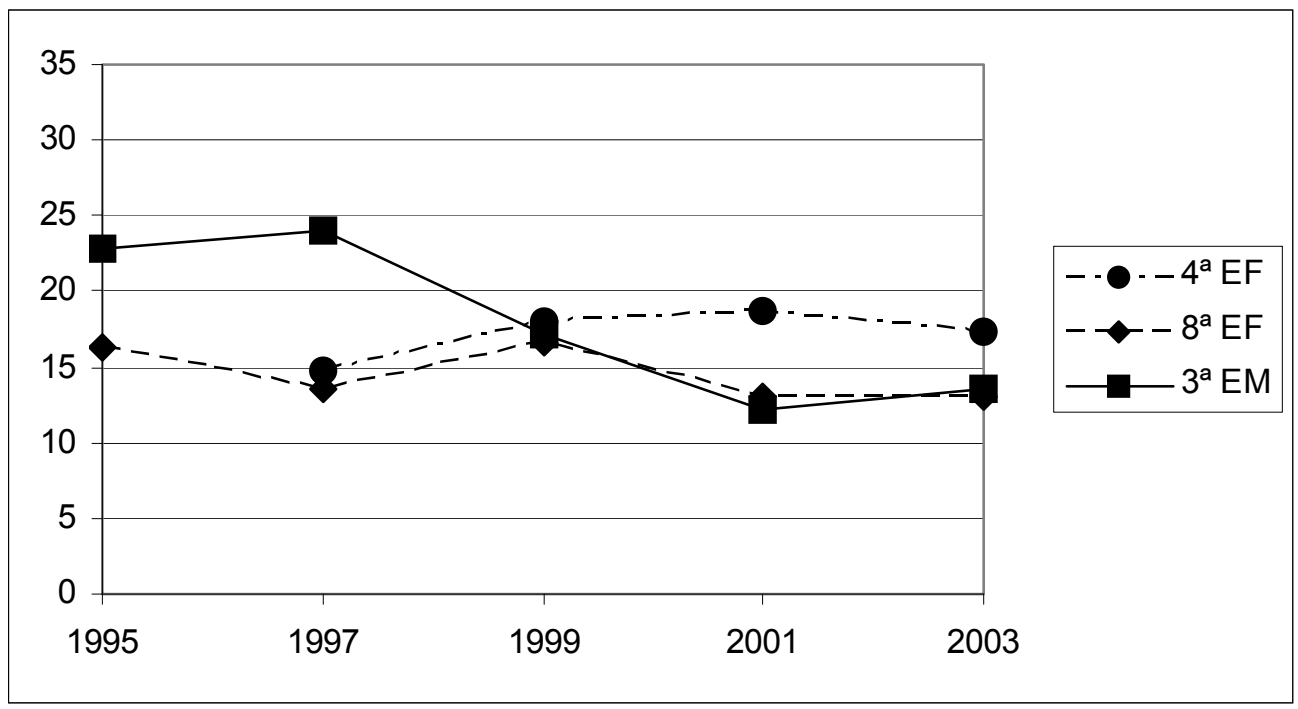

Fonte: elaboração própria com dados do Saeb - Inep/MEC.

Gráfico 5 - Evolução da heterogeneidade das escolas, por série - Rede Estadual, Matemática

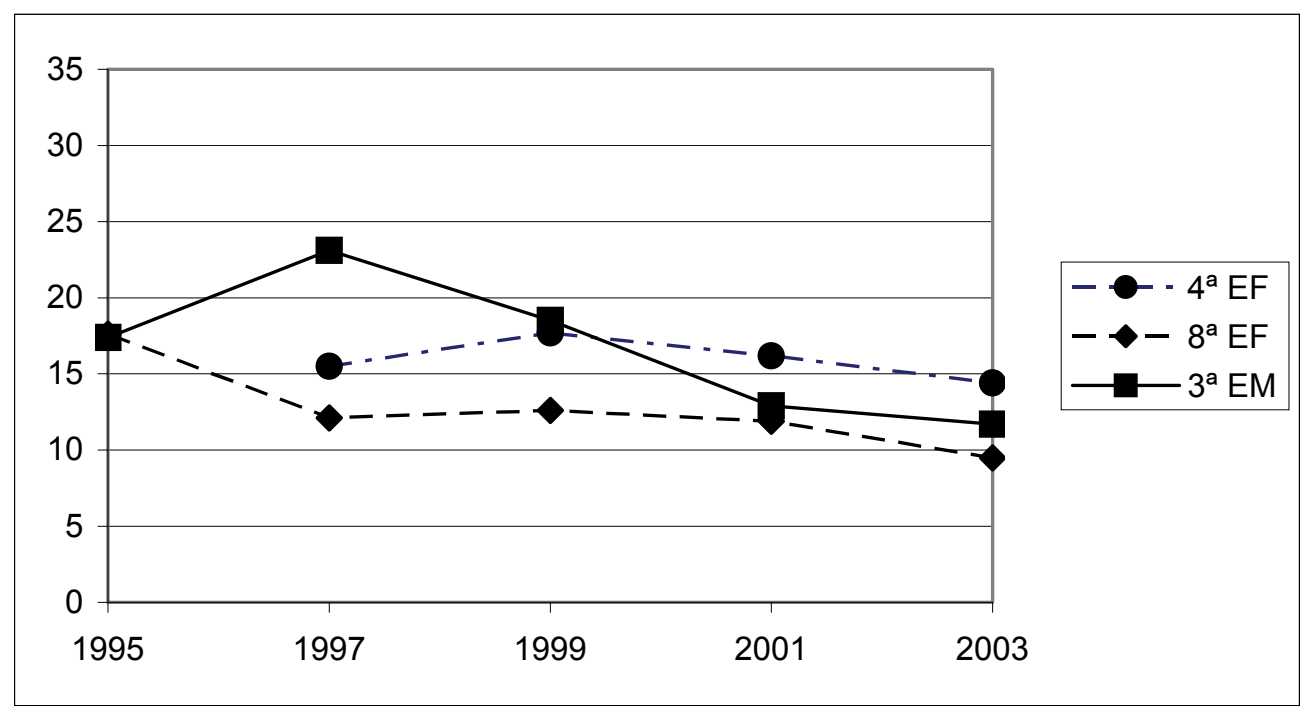

Fonte: elaboração própria com dados do Saeb - Inep/MEC. 
a homogeneidade entre as escolas. Em 1995, segundo os dados do Censo Escolar, somando-se os alunos matriculados no ensino médio na rede municipal e na rede estadual, obtém-se um quantitativo superior a 4.400 .000 matrículas. Em 2001, esse número estava $71 \%$ maior, superando 7.500 .000 matrículas. Durante o mesmo período, as matrículas na rede particular decresceram de pouco mais de 1.170 .000 para um pouco mais de 1.120 .000 alunos matriculados no ensino médio. Esses dados podem ser mais bem visualizados no gráfico 6 .

Os gráficos 7, 8 e 9 apresentam a evolução da heterogeneidade das escolas para cada um dos níveis de ensino, por dependência administrativa. Eles mostram que existem diferenças entre as redes. Essas diferenças, porém, são mais acentuadas na $3^{a}$ série do ensino médio do que na $4^{\mathrm{a}}$ série do ensino fundamental. Esse fato corrobora os resultados mostrados na tabela 2 , em que se percebe uma elevaçáo no porcentual de escolas com $u_{{ }_{j}}$ significativo, em razáo do aumento da escolaridade.

O gráfico 7 confirma que, atualmente, em relação à $4^{a}$ série, as escolas da rede particular brasileira são mais homogêneas, e a rede municipal é a mais heterogênea de todas. Isso, certamente, é fruto dos investimentos na educação feitos por algumas prefeituras nos últimos anos, principalmente em algumas capitais, em detrimento de outras prefeituras que mantêm a duras penas os níveis de ensino pelos quais são responsáveis.

Gráfico 6 - Número de matrículas no ensino médio, por ano e por dependência administrativa

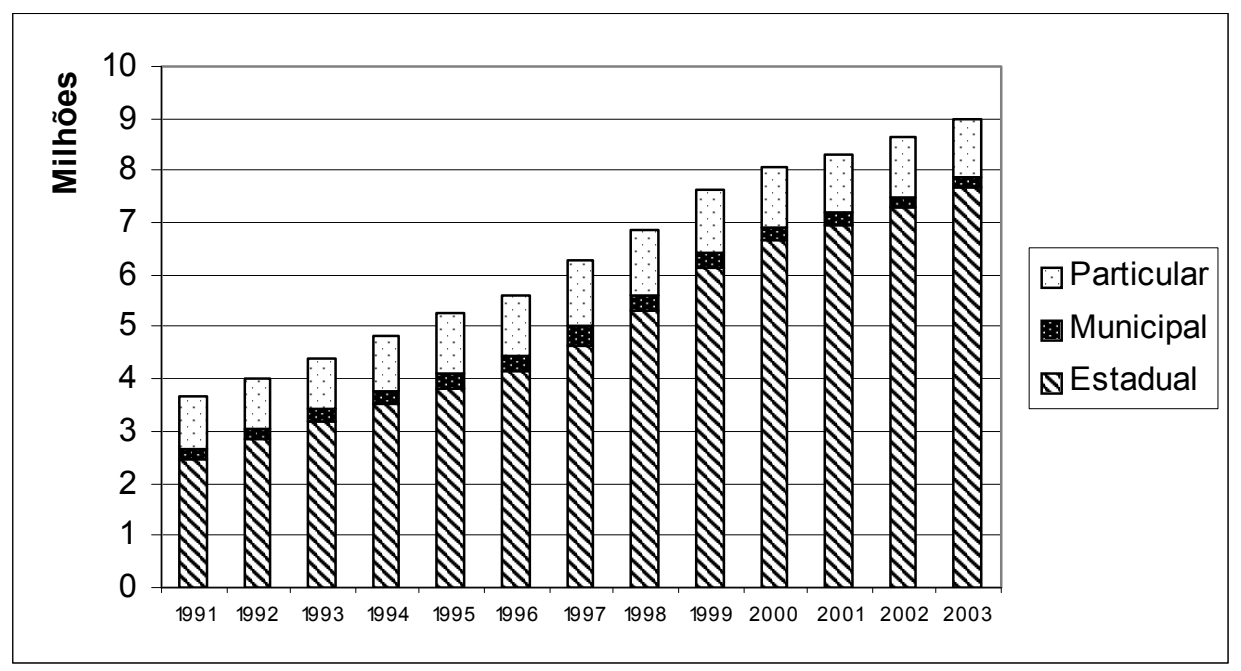

Fonte: elaboração própria com dados do Censo Escolar - Inep/MEC. 
Quando o foco está na $8^{\mathrm{a}}$ série do fundamental, esse cenário muda, e a rede particular começa a agregar escolas mais distintas quanto ao impacto produzido por elas sobre o desempenho cognitivo de seus alunos. Observa-se também que os valores da heterogeneidade vêm sofrendo constante queda, e os maiores porcentuais atingidos em 2003 assemelham-se aos menores de 1995 (Gráfico 8).

Gráfico 7 - Evolução da heterogeneidade das escolas, por rede $-4^{a}$ série $E F$, Matemática

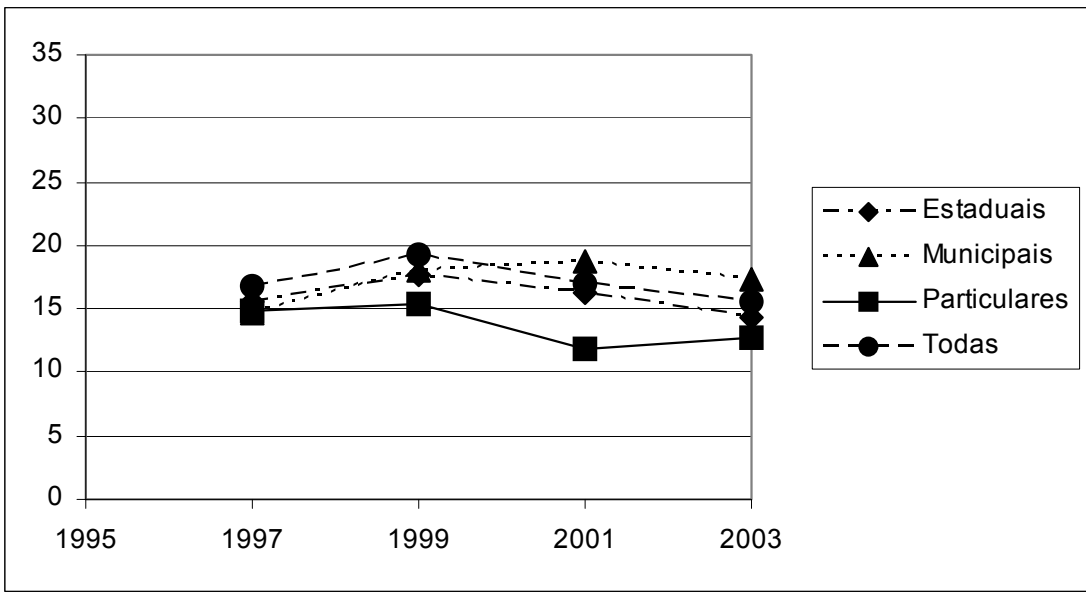

Fonte: elaboração própria com dados do Saeb - Inep/MEC.

Gráfico 8 - Evolução da heterogeneidade das escolas, por rede $-8^{a}$ série $E F$, Matemática

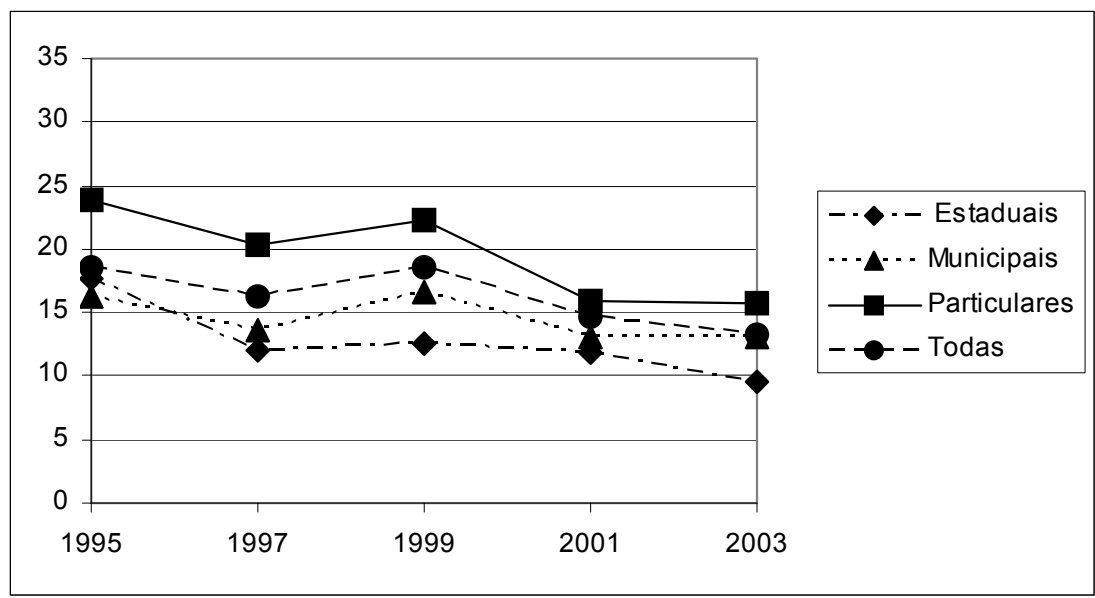

Fonte: elaboração própria com dados do Saeb - Inep/MEC. 
$\mathrm{Na} 3^{\text {a }}$ série do ensino médio as diferenças entre o público e o privado são as maiores dentre as observadas. Nesse nível de ensino, a rede estadual e a municipal assumem valores parecidos para a heterogeneidade. $\mathrm{O}$ destaque fica com a rede particular que atingiu 30\% em 1995, e, em 2003, ostentava quase 25\% (Gráfico 9). Suspeita-se que a rede particular seja mais heterogênea, não só por atender a um alunado mais diversificado, mas também por não estar sujeita a padróes préestabelecidos pelas Secretarias de Educação, como é o caso da rede pública.

\section{Gráfico 9 - Evolução da heterogeneidade das escolas, por rede $-3^{a}$ série $\mathrm{EM}$, Matemática}

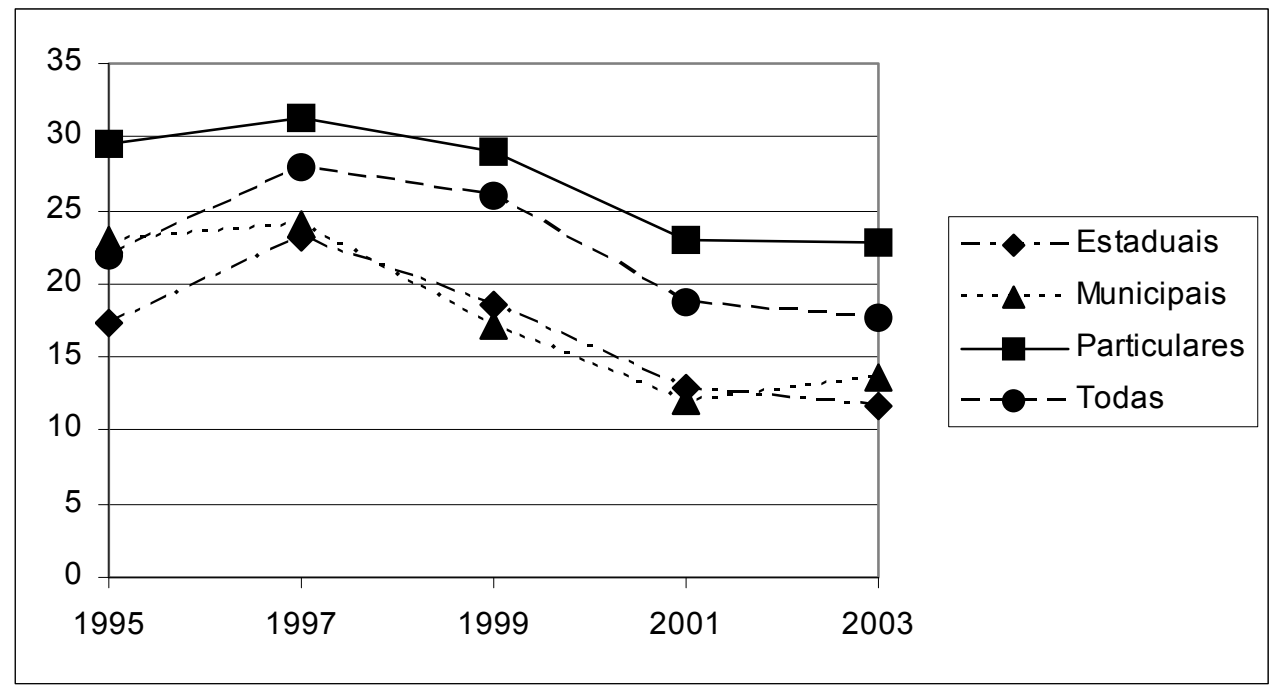

Fonte: elaboração própria com dados do Saeb - Inep/MEC.

\section{CONCLUSÕES: A ESCOLA PODE FAZER A DIFERENÇA}

A relevância das discussóes sobre o efeito da escola já está mais do que consolidada. No entanto, é preciso lembrar que o cálculo desse efeito é apenas o primeiro passo para a busca de fatores que explicam os resultados alcançados. Ou seja, há um caminho a ser percorrido para se conectar a eficácia e o melhoramento escolar (Hopkins; Stringfield, 2000 apud Brooke; Soares, 2008).

Os impactos desses resultados para as políticas públicas educacionais e para as futuras pesquisas do país, nessa linha de efeito da escola, relacionam-se com o fato de que somos mais parecidos com a situaçáo internacional do que é usual admitir. Nossa medida de heterogeneidade apresenta uma média de 15\%, quando a disciplina é a 
Língua Portuguesa, aproximando-se dos 10\% que caracteriza os países desenvolvidos. Por outro lado, ainda que existam semelhanças, há escolas de destaque. Tais expoentes também podem funcionar como referencial para a formulação de políticas públicas, visando a melhoria da educação com base na melhoria da escola.

No entanto, a variação existente, quando se analisam os subconjuntos de escolas dentro do sistema educacional como um todo, é muito grande. Para os subconjuntos analisados, tem-se desde $9,5 \%$ até $31,2 \%$. Isso é um indicador de que existem diferenças significativas entre redes ou entre séries, em relação à heterogeneidade das escolas; portanto, a média dessa medida não caracteriza bem a diversidade do sistema educacional brasileiro.

Um registro fundamental para esse tipo de análise quantitativa da heterogeneidade das escolas, que às vezes é negligenciado em trabalhos da área, refere-se ao fato de que essa medida só faz sentido quando o modelo multinível escolhido tem apenas o intercepto aleatório (Raudenbush; Willms, 1995). No caso do modelo (1) adotado neste trabalho, observe-se que o intercepto $\beta_{0 \mathrm{j}}$ possui sua parte randômica. Mas os demais fatores, tais como $\beta_{1 j}, \beta_{2 j}$ etc., estão fixos, possibilitando assim o cálculo da partição da variância feito no item 4. Portanto, a medida de efeito da escola, $u_{0 j}$, é mais geral, pois ela estará presente como resultado de qualquer modelo implementado, ao contrário da medida de heterogeneidade que depende das restriçóes dos modelos já citadas anteriormente (Raudenbush; Willms, op. cit.).

Em termos de efeito da escola propriamente dito, e não de heterogeneidade, percebe-se que no Brasil a escola também faz diferença. Pode-se afirmar, portanto, que o estabelecimento de metas de desempenho deveria ser tema freqüente nas discussóes acadêmicas e governamentais, de tal forma que as práticas internas às escolas pudessem ser constantemente fomentadas, visando a um aumento do resultado final.

Neste trabalho, propôs-se a diferenciação conceitual entre heterogeneidade das escolas e efeito das escolas, com base nas evidências empíricas apresentadas. Apesar disso, quando é possível calcular as duas medidas, é preciso observar que ambas as definições baseiam-se nos mesmos princípios básicos, isto é, utilizam os mesmos elementos de um modelo hierárquico, que fora ajustado a um determinado conjunto de dados. A diferença encontra-se no fato de que a heterogeneidade sintetiza tais elementos em um único número, enquanto na outra definição esses elementos são mantidos separados para cada escola. As estimativas dessas variâncias, entre escolas $\sigma_{u 0}^{2}=\operatorname{Var}\left(u_{0 j}\right)$, quanto intra-escola $\sigma_{r}^{2}=\operatorname{Var}\left(r_{i j}\right)$, são fornecidas rotineiramente pelos softwares utilizados para se estimar os modelos hierárquicos; no caso, o HLM é o mais comum, mas, nesta pesquisa, foi utilizado o SPSS 13.0. No entanto, 
pode-se ilustrar o fato de que ambas advêm dos mesmos elementos de um modelo, calculando-se a medida da heterogeneidade diretamente com base nos valores das variâncias dos $u_{0 j}$ e dos $e_{i j}$. Esta estimativa mostra que na realidade os dois conceitos de efeito da escola são similares e consistem em dar ênfase a aspectos diferentes de parâmetros do modelo de análise, situação comprovada pela convergência dos resultados apresentados na tabela 2 e nos gráficos 7,8 e 9.

A princípio, parece que existe uma relação entre as duas formas de se calcular a heterogeneidade e o número de alunos. $\mathrm{Na} 4^{\mathrm{a}}$ série do ensino fundamental da rede pública, o número de alunos e de escolas é bem maior que na $3^{\text {a }}$ série do ensino médio da mesma rede, e, à medida que o número de alunos diminui, também diminui a diferença. Mas isso é apenas uma constatação e não uma explicação do ocorrido.

Considerando o modelo base escolhido, pôde-se propor análises a respeito do impacto do efeito da escola sobre a qualidade do sistema educacional brasileiro. No entanto, outras análises, não implementadas aqui, podem ser feitas a partir de configuraçóes diversas do modelo base. Pode-se citar, por exemplo, a análise do efeito da escola sobre a eqüidade socioeconômica. Nesse caso, o nível 1 do modelo base seria mantido, enquanto o nível 2 seria ligeiramente modificado. Pode ser observado abaixo que a medida de interesse, nesse caso, seria o $u_{l j}$, uma vez que o modelo passaria a ter náo só o intercepto aleatório, mas também inclinaçóes distintas para cada escola, no que se refere ao impacto do nível socioeconômico dos alunos sobre o seu desempenho cognitivo. Outras configuraçóes também poderiam ser propostas e, conseqüentemente, novos estudos realizados.

Nível 1: $\quad Y_{i j}=\beta_{0 j}+\beta_{1 j} N_{i j}+\beta_{2 j} \operatorname{SEXO}_{i j}+\beta_{3 j}$ PARDO $_{i j}+\beta_{4 j}$ PRETO $_{i j}+$

$$
\beta_{5 j} \text { ATRASO }_{i j}+\beta_{6 j} \text { DISCIPLINA }_{i j}+\beta_{7 j} \operatorname{ATITUDE~}_{i j}+r_{i j}
$$

Nível 2: $\quad \beta_{0 j}=\gamma_{00}+\gamma_{01}$ MNSE $_{j}+\gamma_{02}$ REDE $_{j}+\gamma_{03}$ MATRASO $_{j}+u_{0 j}$

$$
\begin{aligned}
& \beta_{1 j}=\gamma_{10}+u_{1 j} \\
& \beta_{2 j}=\gamma_{20} \\
& \beta_{3 j}=\gamma_{30} \\
& \beta_{4 j}=\gamma_{40} \\
& \beta_{5 j}=\gamma_{50} \\
& \beta_{6 j}=\gamma_{60} \\
& \beta_{7 j}=\gamma_{70}
\end{aligned}
$$


E o último ponto, mas talvez o mais importante de todos, refere-se ao fato preocupante que distingue o sistema educacional brasileiro dos sistemas dos países desenvolvidos ora citados. Como visto anteriormente, ambos apresentam uma medida de heterogeneidade baixa, porém, uma coisa é apresentar semelhança entre as escolas, mas com alto desempenho dos seus alunos; outra, completamente diferente, é apresentar semelhança entre as escolas, mas com baixo desempenho. Infelizmente, o Brasil se encontra nessa última situação, que poderia ser caracterizada como uma "homogeneidade perversa". Resultados de estudos internacionais, como o PISA, comprovam esse baixo desempenho. Utilizando, também, dados do próprio Saeb, o movimento "Todos pela Educação" " mostra que o porcentual de alunos brasileiros, com desempenho cognitivo adequado à série que estáo cursando, é muito pequeno, principalmente em Matemática. As tabelas 3 e 4 retratam essa realidade para os cinco ciclos do Saeb estudados nesta pesquisa, ou seja, a despeito de nossa medida de heterogeneidade ser comparável à medida dos países desenvolvidos, seria um equívoco comparar as nossas escolas com as deles.

\footnotetext{
${ }^{6} \mathrm{O}$ projeto "Todos pela educação" é uma iniciativa da sociedade civil, da iniciativa privada, de organizaçóes sociais, educadores e gestores públicos de educação que tem como objetivo garantir educação básica de qualidade para todos os brasileiros até 2022, bicentenário da independência do país. A atuação do movimento inclui o monitoramento da educação por meio da divulgaçáo de pesquisas, dados e informaçóes relacionados ao tema; a maior e melhor inserção da educação na mídia, o fomento ao debate e à mobilização, e o estímulo à formação de agendas locais de acompanhamento, cobrança e apoio. Para alcançar a educação que o Brasil precisa, foram definidas cinco metas específicas, simples, compreensíveis e focadas em resultados mensuráveis, que devem ser atingidas até 7 de setembro de 2022: (1) Toda criança e jovem de 4 a 17 anos na escola. (2) Toda criança plenamente alfabetizada até os 8 anos. (3) Todo aluno com aprendizado adequado à sua série. (4) Todo jovem com o Ensino Médio concluído até os 19 anos. (5) Investimento em educação ampliado e bem gerido. As metas, comunicadas constantemente, servirão como direcionamento para que todos os brasileiros acompanhem e cobrem melhorias na educação. Maiores informações sobre o movimento podem ser consultadas no sítio <http://www.todospelaeducacao.com.br $>$.
} 
Tabela 3 - Porcentual de alunos do Brasil com desempenho adequado* à sua série em Matemática

\begin{tabular}{cccccc}
\hline Série escolar & Saeb 1995 & Saeb 1997 & Saeb 1999 & Saeb 2001 & Saeb 2003 \\
\hline $4^{\text {a }} \mathrm{EF}$ & 20,3 & 22,3 & 15,1 & 16,1 & 16,8 \\
$8^{\mathrm{a}} \mathrm{EF}$ & 17,1 & 17,1 & 13,2 & 13,4 & 14,6 \\
$3^{\text {a }} \mathrm{EM}$ & 10,9 & 17,9 & 11,9 & 11,6 & 12,4 \\
\hline
\end{tabular}

Fonte: Todos pela educação.

* Na 4a EF foram considerados os alunos com desempenho superior a 225 pontos; na $8^{\mathrm{a}} \mathrm{EF}$ os alunos com desempenho superior a 300 pontos; e na $3^{\text {a }} \mathrm{EM}$ os alunos com desempenho superior a 350 pontos. Todos esses valores foram retirados da Meta 3 do compromisso "Todos pela educação".

Tabela 4 - Porcentual de alunos do Brasil com desempenho adequado* à sua série em Língua Portuguesa

\begin{tabular}{cccccc}
\hline Série escolar & Saeb 1995 & Saeb 1997 & Saeb 1999 & Saeb 2001 & Saeb 2003 \\
\hline $4^{\text {a } E F}$ & 42,3 & 36,7 & 26,0 & 25,6 & 28,1 \\
$8^{\text {a } E F}$ & 38,2 & 32,4 & 18,6 & 21,8 & 20,0 \\
$3^{\text {a EM }}$ & 45,3 & 39,7 & 27,6 & 25,8 & 26,9 \\
\hline
\end{tabular}

Fonte: Todos pela educação.

* Na $4^{\mathrm{a}} \mathrm{EF}$ foram considerados os alunos com desempenho superior a 200 pontos; na $8^{\mathrm{a}} \mathrm{EF}$ os alunos com desempenho superior a 275 pontos; e na $3^{\text {a }} \mathrm{EM}$ os alunos com desempenho superior a 300 pontos. Todos esses valores foram retirados da Meta 3 do compromisso "Todos pela educação".

\section{REFERÊNCIAS BIBLIOGRÁFICAS}

ALBERNAZ, A.; FRANCO, C.; FERREIRA, F. H. G. Qualidade e eqüidade no ensino fundamental brasileiro. Pesquisa e Planejamento Econômico, Rio de Janeiro, v. 32, n. 3, p. 453-476, 2002. ANDRADE, M.; FRANCO, C.; CARVALHO, J. B. P. Gênero e desempenho em matemática ao final do ensino médio: quais as relações. Estudos em Avaliação Educacional, n. 27, p. 77-95, jan./jul. 2003.

BARBOSA, M. L. de O. A Qualidade da escola e as desigualdades raciais no Brasil. In: SOARES, S. et al. (Org.). Os Mecanismos de discriminação racial nas escolas brasileiras. Rio de Janeiro: IPEA, 2005.

BARBOSA, M. E. F.; FERNANDES, C. A Escola brasileira faz diferença? uma investigação dos efeitos da escola na proficiência em matemática dos alunos da 4a série. In: FRANCO, C. (Org.). Avaliação, ciclos e promoção na educação. Porto Alegre: Artmed, 2001.

BRASIL. Ministério da Educação. Instituto Nacional de Estudos e Pesquisas Educacionais Anísio Teixeira. Microdados do Sistema Nacional de Avaliação da Educação Básica 1995, 1997, 1999, 
2001 e 2003. Brasília: Diretoria de Tratamento e Disseminação de Informações Educacionais/ INEP/MEC, 2006. 5 CD-Roms.

BRASIL. Ministério da Educação; Unicef. Aprova Brasil: o direito de aprender; boas práticas em escolas públicas avaliadas pela Prova Brasil. Brasília: MEC, 2006. Disponível em: <http:// www.inep.gov.br/download/imprensa/2006/ aprova_brasil.pdf $>$. Acesso em: jul. 2008.

BROOKE, N.; SOARES, J. F. Pesquisa em eficácia escolar: origem e trajetórias. Belo Horizonte: EdUFMG, 2008.

COLEMAN, J. S. et al. Equality of educational laboratory, 1966. Disponível em: <http://www. nwrel.org/scpd/esp/esp95.html>. Acesso em: abr. 2004.

FERRÃO, M. E. Introdução aos modelos de regressão multinível em educação. Campinas: Komedi, 2003.

GOLDSTEIN, H. Modelos da realidade: novas abordagens para a compreensão de processos educacionais. In: FRANCO, C. (Org.). Avaliação, ciclos e promoção na educação. Porto Alegre: Artmed, 2001.

GOLDSTEIN, H.; SPIEGELHALTER, D. J. League tables and their limitations: statistical issues in comparisons of institutional performance. Journal of the Royal Statistical Society, v. 159, n. 3, p. 385-443, 1996.

GOLDSTEIN, H.; THOMAS, S. Using examination results as indicators of school and college performance. Journal of the Royal Statistical Society, v. 159, n. 3, p. 149-163, 1996.

GREMAUD, A. P.; FELÍCIO, F.; BIONDI, R.L. Indicador de efeito escola: uma metodologia para a identificação dos sucessos escolares a partir dos dados da prova Brasil. In: CONGRESSO INTERNACIONAL EM AVALIAÇÃO EDUCACIONAL, 3. Anais do... Fortaleza, 2006. HAMBLETON, R. K.; SWAMINATHAN, H.; ROGERS, H. J. Fundamentals of item response theory. Califórnia: Sage Publications, 1991.

HAMBLETON, R. K. Principles and selected applications of Item Response Theory. In: LINN, R. L. Educational measurement. Washington: American Council on Education and the National Council on Measurement in Education, 1993. p. 147-200.

LEE, V. E. Using multilevel methods to investigate research questions that involve nested data: examples from education. Estudos em Avaliação Educacional, n. 24, p. 47-68, jul./ dez. 2001b.

.What are multilevel questions, and how might we explore them with quantitative methods. Estudos em Avaliação Educacional, n. 24, p. 31-45, jul./dez. 2001a.

NATIS, L. Modelos lineares hierárquicos. Estudos em Avaliação Educacional, n. 23, p. 3-29, jan./jun. 2001.

RAUDENBUSH, S. W.; BRYK, A. S. Hierarchical linear models. Thousand Oaks: Sage, 2002.

RAUDENBUSH, S. W.; WILLMS, J. D. The Estimation of school effects. Journal of Educational and Behavioral Statistics, v. 20, n. 4, p. 307-335, 1995.

SOARES, J. F. O Efeito da escola no desempenho cognitivo de seus alunos. Revista Electrónica Iberoamericana sobre Calidad, Eficácia y Cambio en Educación. v. 2, n. 2, p. 83-104, 2004. Disponível em: <http:// www.ice.deusto.es/rinace/reice/vol2n2/ Soares.pdf>. Acesso em: mar. 2005.

- Avaliação da qualidade da educação escolar brasileira. 2008. Manuscrito.

SOARES, J. F.; ANDRADE, R. J. Escala de posicionamento socioeconômico. In: ENCONTRO DE PESQUISA EM EDUCAÇÃO DA REGIÃO SUDESTE, 7. Anais do... Belo Horizonte: FaE/UFMG, 2005.

SOARES, J. F.; CANDIAN, J. O Efeito da escola básica brasileira: as evidências do Pisa e do Saeb. Revista Contemporânea de Educação, n.4, jul./dez. 2007.

SOARES, J. F.; ALVES, M. T. G.; OLIVEIRA, R. M. O Efeito de 248 escolas de nível médio no vestibular da UFMG nos anos de 1998, 1999 e 2000. Estudos em Avaliação Educacional, n. 24, p. 69-123, jul./dez. 2001.

SOARES, J. F. et al. Fatores associados ao desempenho em língua portuguesa $e$ matemática: a evidência do SAEB 2003. Relatório 
técnico. Belo Horizonte: EdUFMG, 2004.

TEDDLIE, C.; REYNOLDS, D. The International handbook of school effectiveness research. Nova York: Falmer Press, 2000.

VALLE, R. C. Teoria de resposta ao item. Estudos em Avaliação Educacional, n. 21, p.7-91, jan./ jun. 2000.
WILLMS, J. D. Monitoring school performance. Washington: The Falmer Press, 1992. WILLMS, J. D.; RAUDENBUSH, S. W. A Longitudinal hierarchical linear model for estimating school effects and their stability. Journal of Educational Measurement, n. 26, p. 209-232, 1989.

Recebido em: outubro 2008

Aprovado para publicação em: novembro 2008 